\title{
Tooth fragment lodged in the lower lip after traumatic dental: a case report
}

\author{
Chakiri $\mathbf{H}^{1}$, Fawzi $\mathbf{R}^{2}$
}

${ }^{1}$ Dr Chakiri Hanane, Resident in Pediatric and Preventive Dentistry service CCTD - Faculty of Dentistry of Rabat (Morocco), ${ }^{2}$ Dr Fawzi Rachid, Professor of Pediatric and Preventive Dentistry and chief of Department of Pediatric and Preventive DentistryCCTD - Faculty of Dentistry of Rabat (Morocco)

Address for Correspondence : Dr. Hanane Chakiri, E-mail:dr.chakirihanane@gmail.com, Consultation Center of Dental Treatment Rabat - Faculty of Dentistry Avenue Allal El Fassi, Mohammed Jazuli Street - Al Irfane City - BP 6212 Rabat Institutes

\begin{abstract}
In permanent teeth, the crown fracture is often associated with lesions in the surrounding oral tissues particularly at cold which can lead to serious complications.In the presence of a lip edematous, open and / or shredded associated with a coronal fracture, thorough clinical and radiographic examination of soft tissue must be systematic.In fact, lesions of the lip can cover up any foreign bodies or fragments of dental crowns embedded in the wounds. The orbicularis muscle pain on palpation mask their presence making the impalpable and only an X-ray may highlight them.Through this article based on a clinical case, we will describe the process for the diagnosis of including dental fragment at labialis after a dentoalveolar trauma, and the terms of the management.
\end{abstract}

Key-words: Inclusion, Tooth Fragment, Lip, Trauma

\section{Introduction}

Coronary fractures of upper central incisors are often associated with damage to the surrounding tissue including oral labial level [1].

Typically, crown fractures are easily diagnosed, however, when an open wound is lip associated, special attention should be given as to the future of the fractured fragments.Indeed, lesions of the lip can hide any foreign bodies or fragments dental crowns burried in the wound $[2,3]$.

The extent and severity of traumatic injuries of the lip vary from small lacerations to the loss of large pieces of tissue, thus they present a major challenge in terms of reconstruction options and the decision result surgical management.

\section{Case Report}

Ethical approval: Obtained from Institutional Ethics Committee (Human Studies)

Funding: No funding sources.
Conflict of Interest: The authors declare no conflict of interest

A 10 years old female child,consulted the pediatric dentistry department of the Consultations Central and Dental Treatments flap, 24 hours after having a dental maxillary level trauma.

In the interrogation, the child, accompanied by his mother, reported he suffered a direct blow on the chin after a collapse playing scooter.

The general examination didn't reveal any particular general pathology nor known drug allergy.The extraoral examination noted the presence of a lip open wound, deep enough, extending part of the skin to the mucous membrane portion [Fig 1].Its edges were irregular, bruised and dirty appearance.In addition, other oral mucosa showed no apparent traumatic injury and the occlusion was correct.The dental examination showed enamel-dentin fracture without pulp involvement in the coronary third of the maxillary central incisors [Fig 2]. 


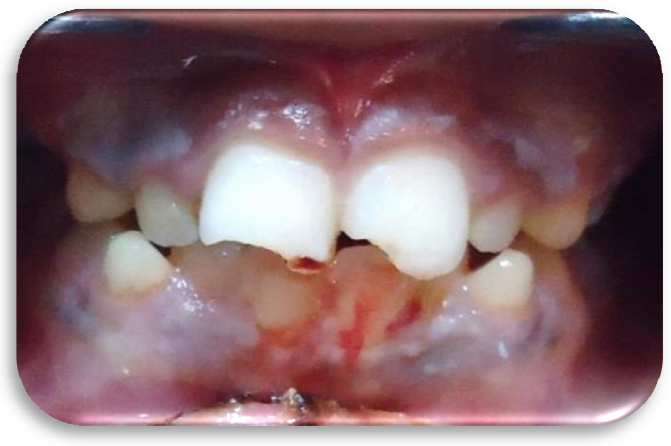

Figure 1: Extraoral view of the patient with upper lip Lacerations

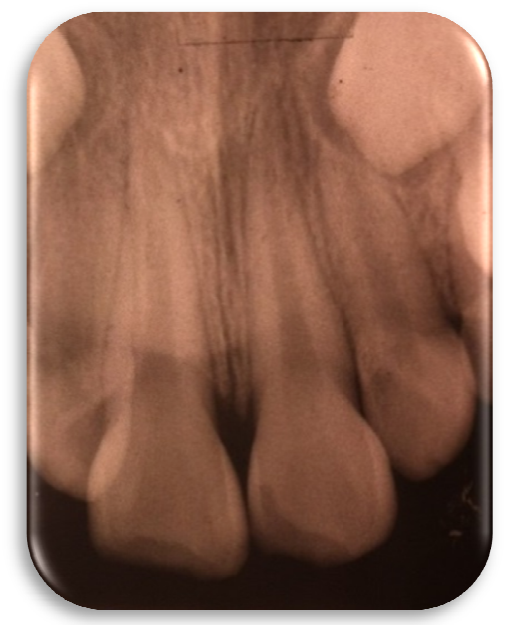

Figure-3: Retro-alveolar radiograph 11, 21 showing a coronal dentin-enamel fracture at pulp without involvement at the 11 and 21

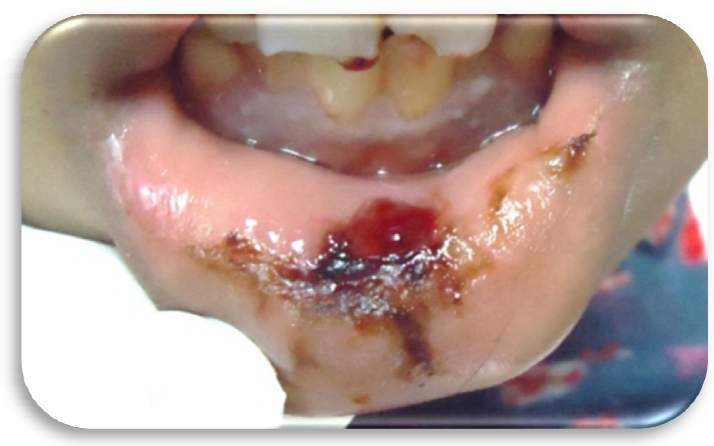

Figure-2: Intraoral view: Coronal fracture of maxillary central incisors 11, 21.

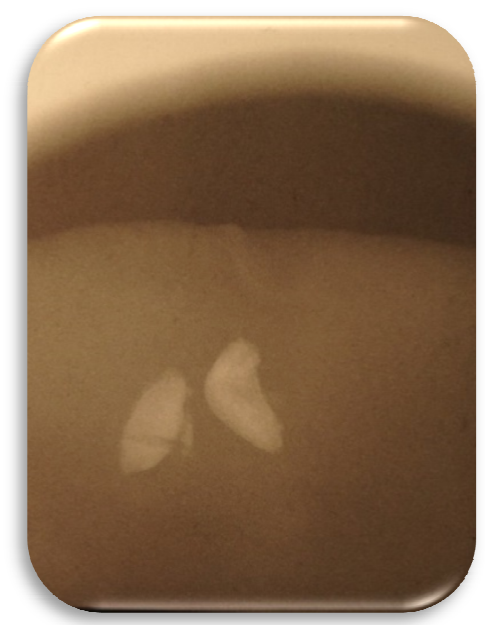

Figure 4:Radiography of the lower lip showing inclusion of two radiopaque fragments

Given the direction and impact of the shock on the chin, we realized a panoramic X-ray which has eliminated any involvement of the temporomandibular joint in the trauma.Reverse cellular X-ray revealed that the two upper central incisors were mature, with absence of any root or bone fracture associated [Fig 3]. The presence of an open lip wound motivated the realization of soft tissue radiography interposed between the lip and lower incisors while reducing the radiation dose by half which allowed us to clearly objectify two opaque body corresponding to shapes, sizes and densities of missing fragments [Fig 4]. The management of our patient involved both lip wound dental fractures.Initially, the wound local anesthesia edges was performed by injecting into the dermis and not through the wound to prevent the spread of germs.The injection was done gradually at low pressure, taking care to avoid intravascular injection, until the orange peel effect on the dermis.The disinfection of edges of the wound and surrounding skin was performed with aqueous iodophor (Betadine $\left.{ }^{\circledR}\right)$, followed by extensive washing with clean saline and gentle brushing of the wound to remove superficial stains.The after one proceeded to the identification of foreign bodies and their careful removal [Fig 5, $6]$.

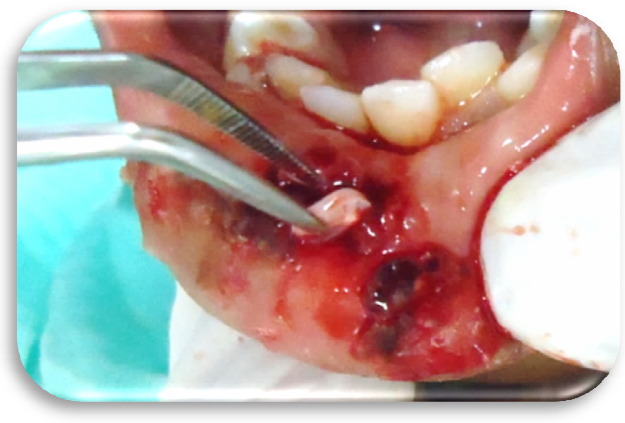

Figure 5: Extraction of fractured tooth fragments

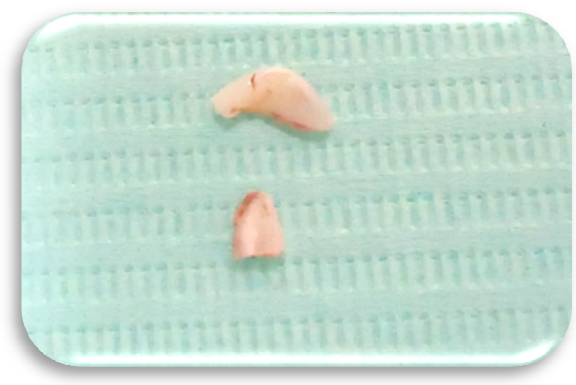

Figure 6: The two fragments fractured 
A first postoperative radiograph of the lip was performed immediately and showed persistence even other small dental fragments [Fig 7].After which a new research and ablation were business until removal of all dental fragments confirmed by radiograph [Fig 8$]$.

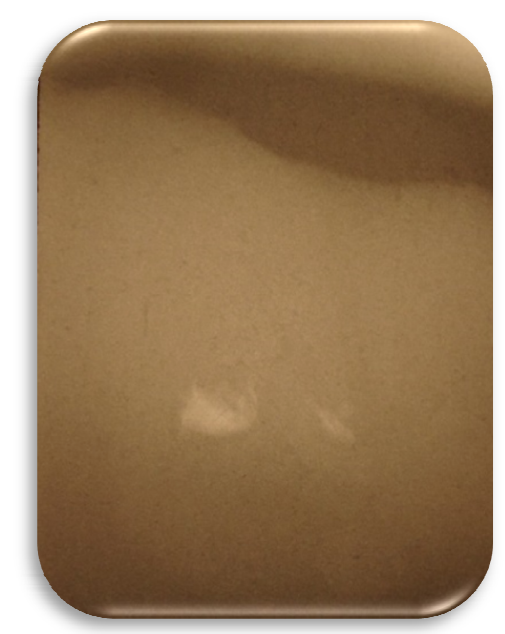

Figure 7:Rmmediate control radiograph showing the persistence of other small dental fragments

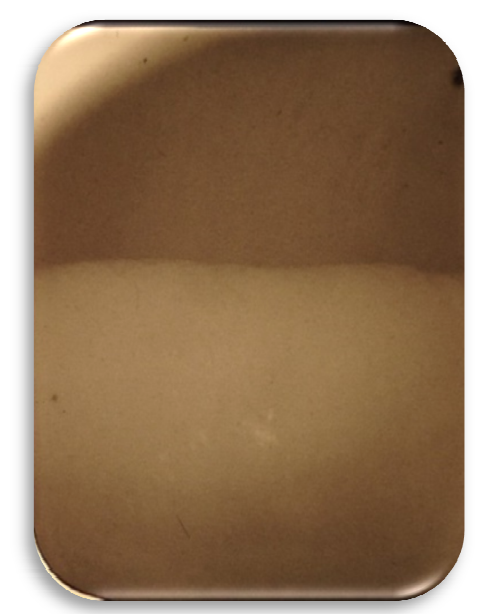

Figure 8:Radiography of the lip after reoperation : elimination of residual fragments

The edges of the wound were brought together and competed well then sutured with simple points using 5.0 for son, for aesthetic reasons [Fig 9]

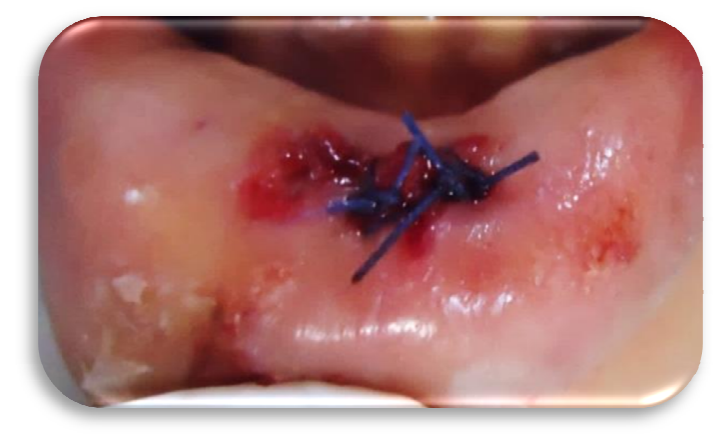

Figure 9: Stitch Up

In the dental fractures, we urgently performed a dentin-pulp protection glass ionomer cement to prevent contamination pulp open dentinal tubili.Cosmetic reconstruction was postponed to a later meeting.The session was ended with the prescription of tetanus vaccine to prevent tetanus AC dreaded case of open skin wound, antibiotic to prevent infection, mouthwash containing chlorhexidineas well as recommendations on diet and maintaining good oral hygiene. After one week, the sutures have been filed and a coronary reconstitution using the composite was made at both upper central incisors [Fig 10, 11].

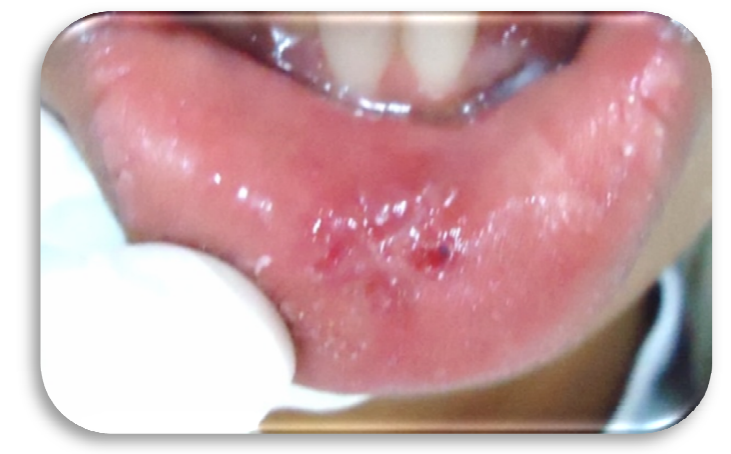

Figure 10: Clinical evaluation after one week: removing sutures points 


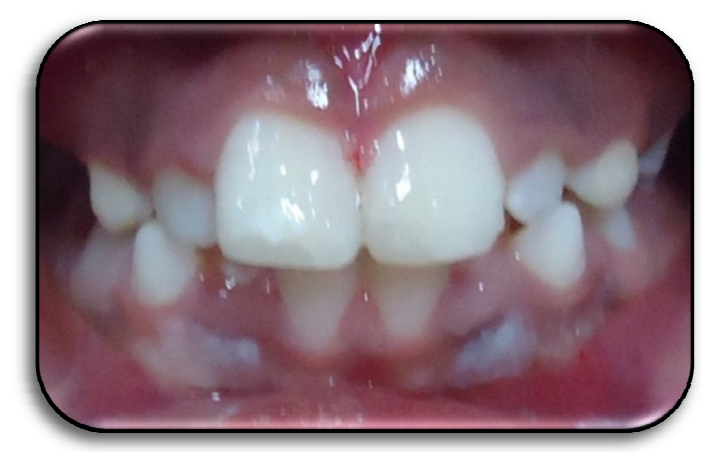

Figure 11: Intraoral view showing the coronal restoration of the composite 11, 21

The patient returned for follow-up at one, two and four weeks after the injury.In each case, the soft tissues were examined clinically and radiographically, with no signs of complications [Fig 12].

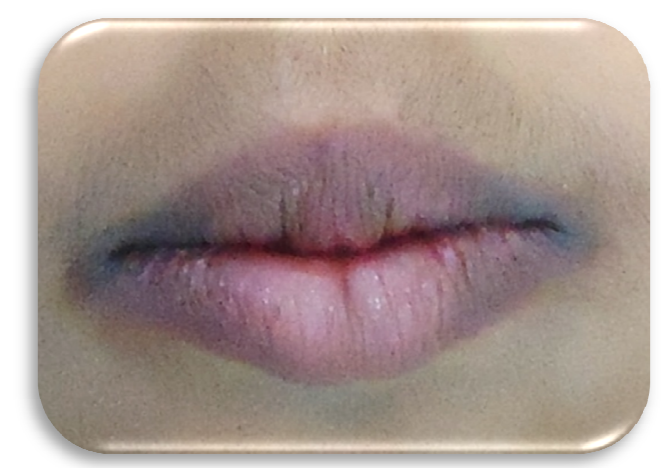

Figure 12: One month after healing of the lip

\section{Discussion}

Open lip sores associated with coronal fractures of the anterior teeth are quite common and can be sources ofvarieties of chronic problems $[4,5,6]$.

The appropriate radiographic evaluation of patients with unfound fractured tooth fragments after maxillofacial trauma is extremely important, since these dental structures may become foreign bodies at risk for ingestion, aspiration or inclusion in the surrounding tissues.

The worst complication is aspiration of foreign bodies that can cause the patient to a variety of chronic respiratory problems and even death if not diagnosed early $[7,8,9]$.

In our patient, the presence of enamel-dentin fracture at the upper central incisors, associated with edematous lower lip with an open wound motivated the realization of an X-ray performed at the level of the lower lip which confirmed the presence of these foreign bodies in injured tissues [Fig 4].
The aim of treatment is to prevent wound infection, restore the skin continuity and achieve a good cosmetic result while causing the least possible discomfort to the child.In the presence of bruised and soiled by the presence of foreign body wounds, infection is a major risk of infection increases with the support period.Washing with saline is a key time.Antisepsis the injured area appealed preferably povidone iodine or sodium hypochlorite, possibly with chlorhexidine.

The surgery was performed under local anesthesia.The use of vasoconstrictor has reduced bleeding and increased the local effect.The injection was carried out at the wound edges of the skin side where the pain receptors are many and never through the wound to prevent the spread of germs.The tissues of the lower lip were raised and dismissed.Teeth fragments were carefully located and individually deleted [Fig 5,6].

Effective detection of the presence of residual fractured fragments can be made difficult by a series of factors such as laceration, bleeding, edema and fragmentation 
that can hide.It has been well established that small fragments of teeth introduced into the lower lip are continuously subjected to movements, due to the contraction of the orbicularis muscle and can be moved in an unpredictable direction beyond the point of entry $[10,11,12]$.

The persistence of dental fragments can be the source of infection, vascular and nerve damage and scarring flanges.The case reported by Schwengber in 2010 shows the presence of a nodule lip following the non eradication immediate tooth fragment $[13,14,15]$.

To confirm the removal of fragments in our patient, radiographs soft tissues were immediately carried out, whereupon the remaining two fragments were revealed and previews.Traumatic injuries of the lips present major challenges in terms of reconstruction options andresults of surgical treatment $[16,17,18]$.

The lip is important both aesthetically and functionally.Its surgical reconstruction must ensure the restoration of all its anatomical components ie skin layers, muscle and mucous membranes.In our patient, and for aesthetic reasons, the banks of the lip wound were reconciled without tension, then sutured competed well to have a healing by first intention, that will be an evolution without complications in épidémisation 7 days, on average effective consolidation of 4 weeks and a final ripening of 12 to 18 months $[19,20]$.

Some locations are not conducive to sutures by a simple approximation of the banks due to the defect, but at the labial level, the most common pitfall is "false defect" where the banks are immediately discarded by the play of sphincters orbicular muscle of the lips cut by the wound.By bringing the banks with dissecting forceps, one often sees that nothing is missing.

Postoperative recommendations are key to the final result.We must protect wounds by creating a moist environment with the application of an antibiotic ointment (egFucidine ${ }^{\circledR}$ ), instructing parents to regularly clean the wound to prevent crusting, which extends the time of epithelialization and give a less satisfactory cosmetic result.

In the presence of open skin wound, the tetanus vaccination should always be checked and updated,otherwise making a recall or serovaccination.Indeed, tetanus is a dreaded infectious disease that says when the tetanus bacillus managed to invade the body through a wound as small as it is.

\section{Conclusion}

Even if an adequate clinical examination of dentofacial injury is often hindered by soft-tissue edema and bleeding, and is frequently performed under less-thanoptimal circumstances, a soft-tissue laceration associated with a dental injury should always alert the physician to the presence of dental fragment inclusion to the peripheral tissues. In this respect, a plain softtissue radiograph frequently helps to rule out this possibility as presented in this case report. Besides, further diagnostic surveys should be performed if the plain radiographs fail to identify the inclusion, ingestion, or aspiration of these fragments. Also, this paper emphasizes thesignificant role of the dental surgeon consultation before the soft-tissue repair in all orofacial injuries.

\section{References}

1. Andreasen JO. Etiology and pathogenesis of traumatic dental injuries.A clinical study of1,298 cases.Scand J Dent Res 1970;78(4): 329-342.

2. O'Neil DW, Clark MV, Lowe JW, Harrington MS. Oral trauma in children: A hospitalsurvey. Oral Surg Oral Med Oral Pathol 1989;68(6):691-696.

3. McTigue DJ. Diagnosis and management of dental injuries in children. PediatrClinNorthAm 2000;47(5):1067-1084.

4. Andreasen JO, Andreasen FM, Andersson L. Copenaghen: Munkgaard;2007. Traumatic injuries to the teeth

5. Pasini S, Bardellini E, Keller E, Conti G, Flocchini P, Majorana A. Surgical removal and immediate reattachment of coronal fragment embedded in lip. Dental Traumatology 2006;22(3):165-168.

6. Da Silva AC, de Moraes M, Bastos EG, Moreira RW, Passeri LA. Tooth fragment embedded in the lower lip after dental trauma: Case reports. Dent Traumatol 2005;21(2):115-120.

7. Al-Jundi SH. The importance of soft tissue examination in traumatic dental injuries: A case report. Dent Traumatol 2010; 26: 509-511.

8. Gill P, Fleming K. Retained tooth fragment. Br Dent J 2010;208(8):330. 
9. Andersson L, Andreasen JO. Soft tissue injuries. In: Andreasen JO, Andreasen FM, Andersson L, eds. Textbook and color atlas of traumatic injuries to the teeth, ed. 4. Copenhagen: Blackwell Munksgaard; 2007:577-597.

10. Taran A, Har-Shai Y, Y Ullmann, Laufer D Peled IJ.Traumatic selfinflicted dick with embedded tooth fragments in the lower lip.Ann Plast Surg.1994 Apr; 32 (4): 431-3.

11. ZerrinAbbasoglu, GizemOzbay, Gokhan Göçmen, Betul KargulTooth Fragment Lodged in the Upper Lip after-Traumatic Dental.Injury: an Unusual Case Report Acta Stomatol Croat.Traumatic Dental Injury 2011; 45 (4): 280-286.

12. Schweneber GF, CardosoM, Vieira Rde S Bonding of permanent central incisor crown fractured Following radiographic localization of the tooth fragment in the lower lip: a case report Dent Traumatol.2010 December; 26 (6): 532.

13. Nabili V Knott PD.Advanced lip reconstruction: Functional and aesthetic considerations.Facial PlastSurg 2008; 24: 92-104.

14. Shu'bi FM, Hamza OJ, Kalyanyama BM, Simon IN.Human bite injuries in the orofacial area at the Muhimbili National Hospital, Tanzania.BMC Oral Health 2008; 30; 8: 12
15. JaumeRius-Miranda, Lluís Brunet Llobet, Eduard Lahor-Soler, Carlos Mendieta: An unexpected presentation of a traumatic wound on the lower lip: a case report Rius-Miranda et al.Journal of Medical Case Reports 2014, 8: 298

16. WL Adeyemo, OA Taiwo, MO Adeyemi, RA Adewole, OM Gbotolorun Pattern of presentation and management of lip injuries in a hospitalNigerian Nigerian Journal of Clinical Practice April 26, 2015, IP: 41.248.164.157

17. Munerato MC, da Cunha FS, Tolotti A, Paiva RL. Tooth fragments lodged in the lower lip after traumatic dental injury: A case report. Dent Traumatol 2008;24(4):487-489.

18. Reis A, Loguercio AD, Kraul A, Matson E. Reattachment of fractured teeth: A review of literature regarding techniques and materials. Oper Dent 2004;29(2):226-33.

19. De Santana Santos T, Melo AR, Pinheiro RT, Antunes AA, de Carvalho RW, Dourado E. Tooth embedded in tongue following firearm trauma: Report of two cases. Dent Traumatol 2011;27(4): 309-313.

20. Antonio AzoubelAntunesTooth embedded in lower lip following dentoalveolar trauma: Case report and literature review Trauma in Primary/Young Teeth General DentistryNovember/December 2012.

\section{How to cite this article?}

Chakiri H, Fawzi R. Tooth fragment lodged in the lower lip after traumatic dental: a case report. Pediatr Rev: Int J Pediatr Res 2015;2(4):164-169.doi:10.17511/ijpr.2015.i04.23 